\title{
Coupled Inductor-Based Parallel Operation of a qZ-Source Full-Bridge DC-DC Converter
}

\author{
Hyeongmin Lee ${ }^{*}$, Heung-Geun $\mathrm{Kim}^{\dagger}$, Honnyong Cha ${ }^{* *}$, Tae-Won Chun ${ }^{* * *}$, and Eui-Cheol Nho ${ }^{* * * *}$ \\ ${ }^{* \dagger}$ Department of Electrical Engineering, Kyungpook National University, Daegu, Korea \\ ${ }^{* *}$ School of Energy Engineering, Kyungpook National University, Daegu, Korea \\ ${ }^{* * *}$ Department of Electrical Engineering, University of Ulsan, Ulsan, Korea \\ ${ }^{* * * *}$ Department of Electrical Engineering, Pukyong National University, Busan, Korea
}

\begin{abstract}
This study presents a novel transformer isolated parallel connected quasi Z-source (qZ-source) full-bridge DC-DC converter that uses a coupled inductor in both the qZ-source network and output filter inductor. Unlike traditional voltage-fed or current-fed converters, the proposed converter can be open- and short-circuited without damaging switching devices. Therefore, the desired buck and boost functions can be achieved and converter reliability can be significantly improved. All the bulky inductors in the qZ-source network and output filter can also be minimized with the proposed inductor structures. A $4 \mathrm{~kW}$ prototype DC-DC converter is built and tested to verify the performance of the proposed converter.
\end{abstract}

Key words: Buck-boost converter, Coupled inductor, DC-DC converter, Full-bridge, Interleaved PWM, qZ-Source

\section{INTRODUCTION}

Two types of full-bridge (FB) transformer-isolated DC-DC converters generally exist: a voltage-fed (V-fed) FB converter and a current-fed (C-fed) FB converter. Fig. 1 shows two traditional transformer-isolated DC-DC power conversion circuits. The V-fed FB converter [Fig. 1(a)] always has a buck (step-down) function, and the upper and lower switches that consist of a phase leg cannot be short-circuited [1]. Similarly, the C-fed FB converter [Fig. 1(b)] always has a boost (step-up) function, and the upper and lower switches that consist of a phase leg cannot be open-circuited.

Thus, the two traditional DC-DC converters shown in Fig. 1 can only produce an output voltage that is smaller than or larger than the input voltage. Furthermore, they cannot be either short- or open-circuited. Consequently, traditional $\mathrm{V}$-fed and C-fed converters are susceptible to electromagnetic interference (EMI) noise, which considerably impairs their system reliability Quasi Z-source (qZ-source) or Z-source

Manuscript received May 28, 2013; accepted Mar. 14, 2014

Recommended for publication by the Associate Editor Pat Wheeler.

${ }^{\dagger}$ Corresponding Author: kimhg@knu.ac.kr

Tel: +82-53-950-5605, Fax: +82-53-950-6600, Kyungpook Nat'l Univ.

*Dept. of Electrical Eng., Kyungpook National University, Korea

${ }^{* *}$ School of Energy Eng., Kyungpook National University, Korea

**** Dept. of Electrical Eng., University of Ulsan, Korea

${ }^{* * * * *}$ Dept. of Electrical Eng., Pukyong National University, Korea converters or inverters are introduced to overcome the aforementioned problems [1]-[3]. Fig. 2 shows an example of a transformer-isolated qZ-source FB DC-DC converter.

By using a qZ-source network that consists of a diode, two inductors, and two capacitors, the main switches $\left(S_{1}\right.$ to $\left.S_{4}\right)$ can be short- and open-circuited without damaging the switching devices. Therefore, the desired buck and boost functions can be achieved, which is appropriate for converters with a having wide input voltage range.

Parallel-connected power converters operate via a general method that easily increases power level in the power electronics area. Through parallel operation, low current rating semiconductor devices can be used without over-sizing a converter module [4]-[6]. When multiple converters are connected in parallel, an interleaved pulse-width modulation (PWM) method is widely used to decrease input and output current ripples. Consequently, this method can reduce input and output capacitor volumes and increase converter efficiency.

Although a qZ-source converter is resistant to EMI noise because of the presence of a qZ-source network, the two inductors and two capacitors in the qZ-source network are heavy and bulky even if the two inductors $L_{1}$ and $L_{2}$ are coupled. The switching frequency of the converter should be increased to decrease the size of passive components. Increasing switching frequency, however, reduces converter 


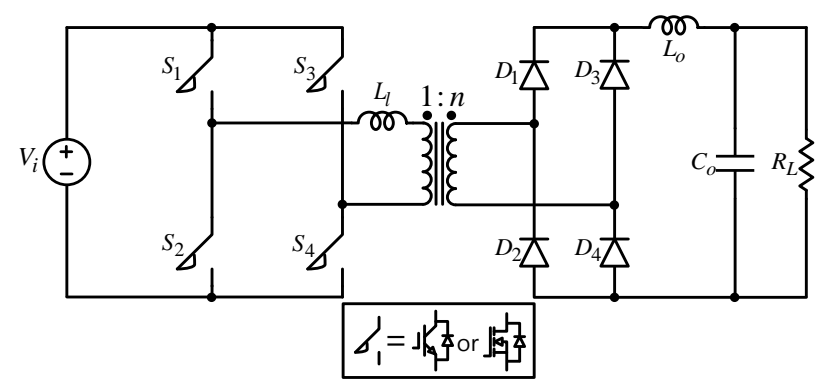

(a) V-fed FB DC-DC converter.

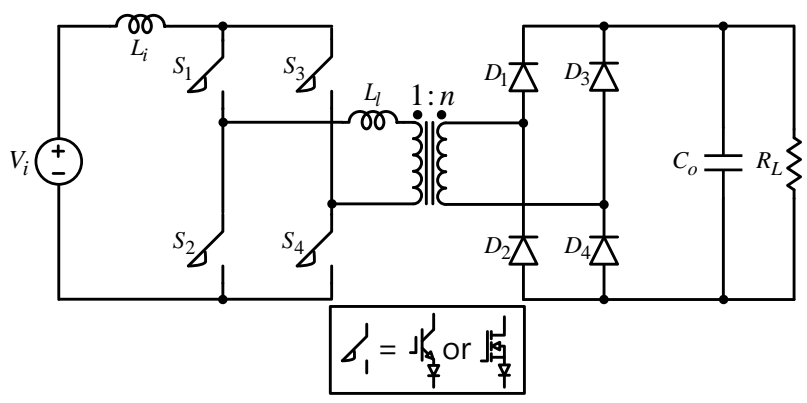

(b) C-fed FB DC-DC converter.

Fig.1. Traditional FB DC-DC converters.

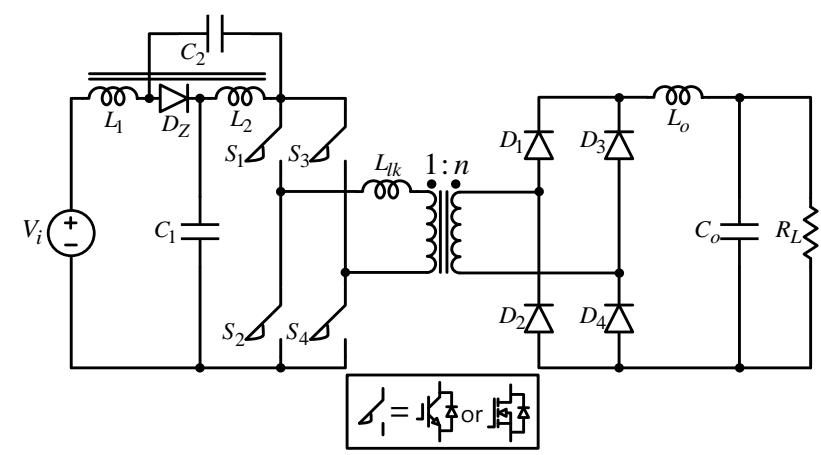

Fig. 2. qZ-source FB DC-DC converter.

efficiency.

This study presents a novel transformer-isolated and parallel-connected FB DC-DC converter a qZ-source network is used to achieve the desired buck and boost functions and increase converter reliability. A specially designed coupled inductor is also used in both the qZ-source network and output filter inductor to minimize inductor current ripple and volume significantly.

With this structure, the proposed DC-DC converter exhibits the following advantages over conventional converters.

- The proposed converter can be short- and open-circuited without damaging switching devices.

- The converter can operate in a wide input voltage range because it has buck and boost functions.

- The converter can be easily applied to a high power converter system through parallel operation.

This paper is organized as follows. The principal operation of the proposed converter is reviewed in Section II. A study on the comparative analysis of current ripples on the non-coupled inductor and coupled inductor is presented in Section III. Experiment results to verify are illustrated in Section IV. Lastly some conclusions and application of the proposed converter are given in Section V.

\section{Principal Operation of The Proposed PARALLEL CONNECTED QZ-SOURCE FB DC-DC CONVERTER}

Fig. 3 shows the overall circuit configuration of the proposed DC-DC converter. Two identical transformer-isolated qZ-source FB DC-DC converters are connected in parallel to increase the power rating of the converter. Conventional two-phase interleaved PWM switching is applied. Therefore, the top and bottom converters are switched at $90^{\circ}$ apart, which results in a $180^{\circ}$ phase shift at the top and bottom qZ-source networks and output filter inductors because of the FB structure.

As mentioned in Section I, the inductors in the qZ-source network are heavy and take a significant portion of the entire converter. All the inductors ( $L_{1}$ to $L_{4}$ ) at the top and bottom qZ-source networks are coupled to decrease inductor size. The two output filter inductors $\left(L_{o 1}\right.$ and $\left.L_{o 2}\right)$ are also coupled by following a similar method.

\section{A. Buck Mode Operation $\left(V_{i}>V_{o}\right)$}

When $V_{i}>V_{o}$, the proposed converter operates in buck mode. No shoot-through interval occurs in buck mode, and thus, diodes $D_{z 1}$ and $D_{z 2}$ in the qZ-source networks are always conducting. No energy is stored in the qZ-source inductors; hence,

$$
V_{C_{1}}=V_{C_{3}}=v_{p n 1}=v_{p n 2}=V_{i} .
$$

Consequently, the proposed converter operates as the conventional parallel-connected V-fed FB DC-DC converter that uses PWM control. Defining D as the effective duty ratio in the output filter side, the voltage gain of the proposed converter in this mode is expressed as follows:

$$
\frac{V_{o}}{V_{i}}=n D
$$

where $\mathrm{n}$ is the transformer turns ratio.

\section{B. Boost Mode Operation $\left(V_{i}<V_{o}\right)$}

In the boost mode, a shoot-through interval occurs at the gate signal, and energy is stored in the qZ-source inductors. The well-known voltage equations in the shoot-through (boost) mode are as follows:

$$
\begin{gathered}
V_{C_{1}}=V_{C_{3}}=\left(\frac{1-D_{s h}}{1-2 D_{s h}}\right) V_{i}, \\
V_{p n 1}, V_{p n 2}=\left(\frac{1}{1-D_{s h}}\right) V_{i},
\end{gathered}
$$

where $D_{s h}$ is the switch shoot-through duty ratio of the 


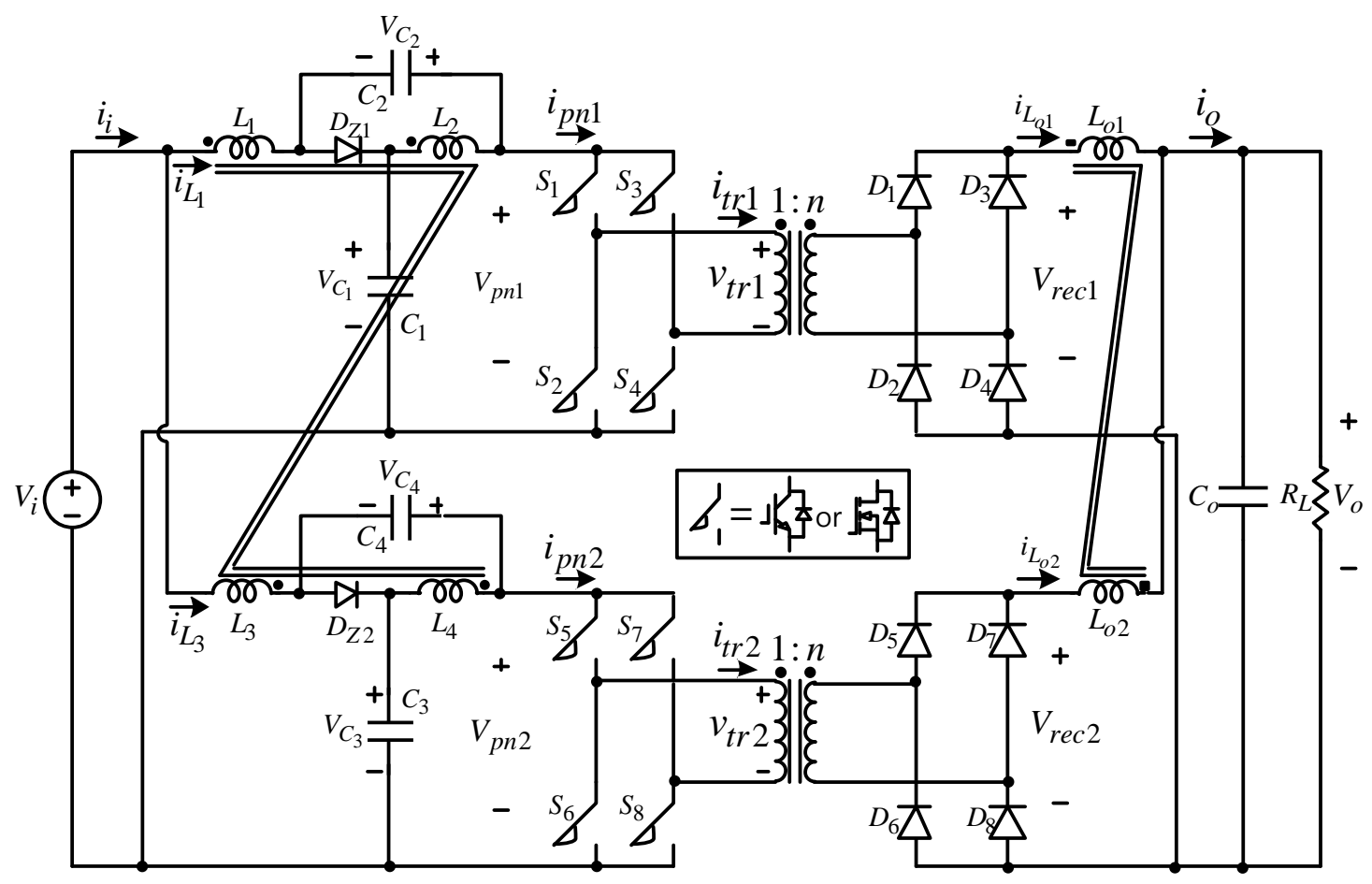

Fig. 3. Proposed parallel-connected qZ-source FB DC-DC converter that uses a coupled inductor.

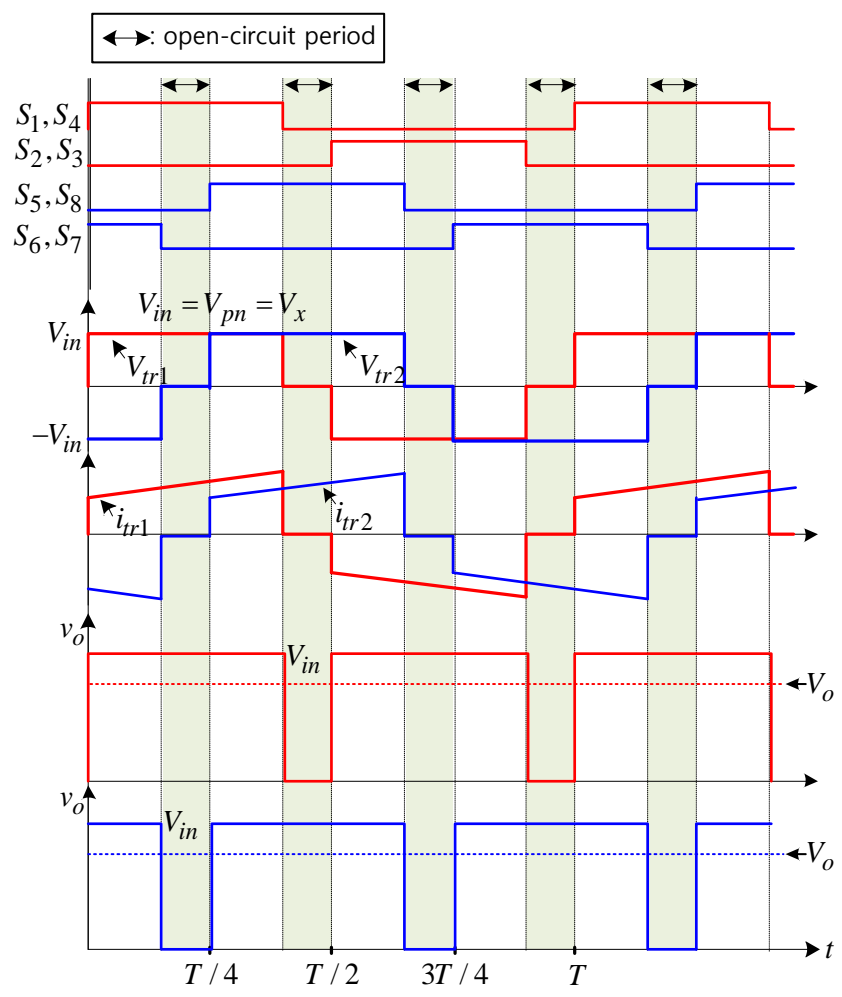

(a) Buck mode.

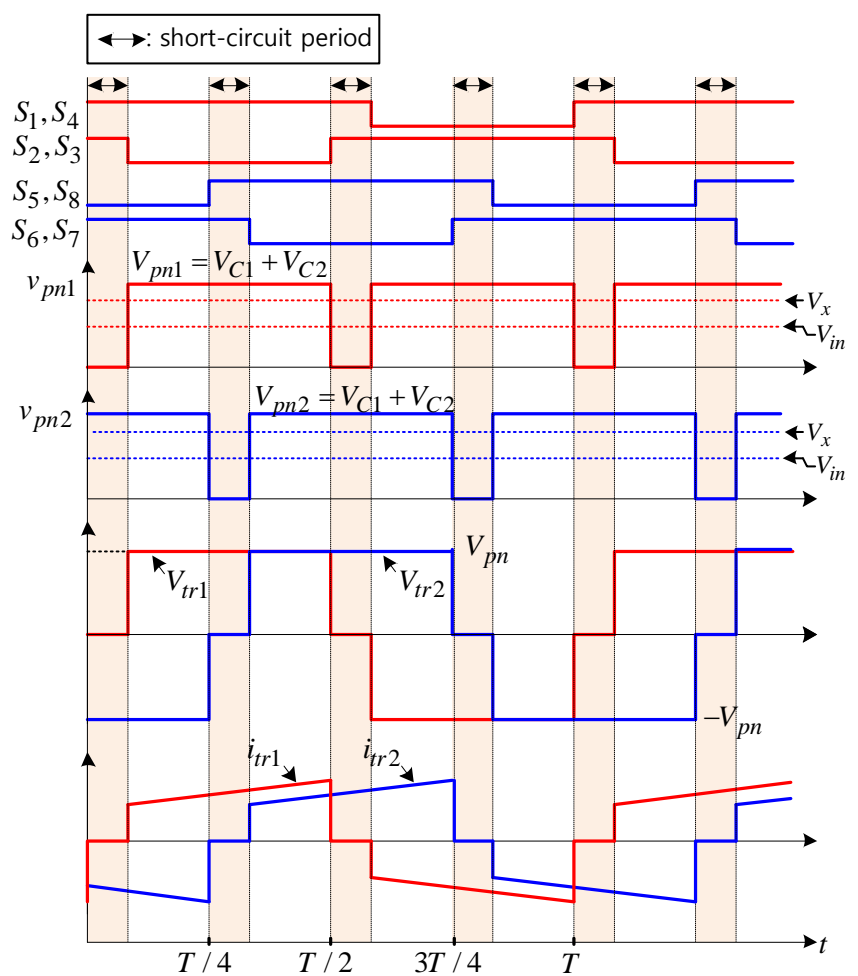

(b) Boost mode.

Fig. 4. Key waveforms of the proposed parallel-connected qZ-source FB DC-DC converter. 


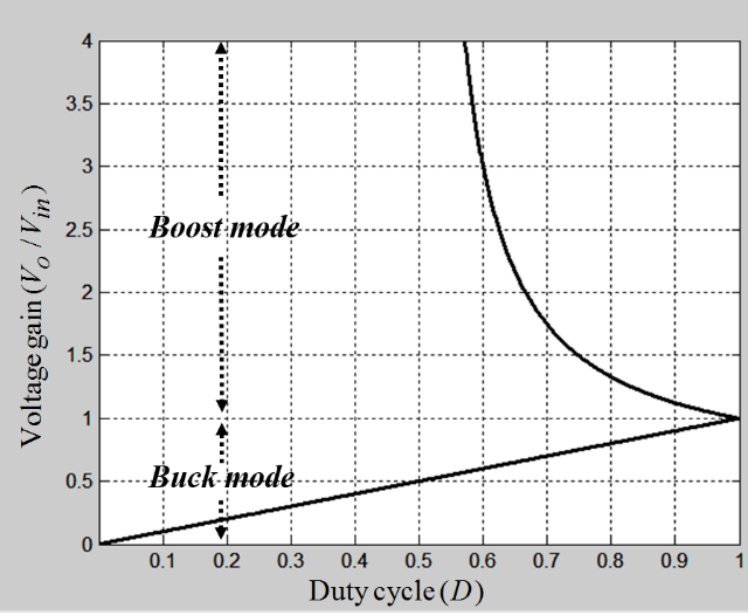

Fig. 5. Voltage gain of the proposed converter $(n=1)$.

converter that is defined as $D_{s h}=1-D$.

Therefore, the voltage gain of the proposed converter in the boost mode is expressed as follows:

$$
V_{o}=n\left(\frac{1-D_{s h}}{1-2 D_{s h}}\right) V_{i} .
$$

Given that $D_{s h}=1-D$, Equation (5) can be rewritten as follow:

$$
V_{o}=n\left(\frac{D}{2 D-1}\right) V_{i}
$$

Fig. 5 shows the voltage gain plot of the proposed converter as $D$ varies when $n=1$. As expected, the desired buck- and boost functions can be achieved by modulating $\mathrm{D}$.

Fig. 4 shows the key waveforms of the proposed converter in both buck and boost modes. Given the interleaving effect, the output (or input) current ripple is reduced. However, all inductor current ripples are not reduced even with the interleaving action. Thus, they remain bulky and heavy. A coupled inductor is used in this study to decrease inductor current ripples.

\section{THE COUPLED INDUCTOR AND ITS EFFECTS}

This section discusses the effect of the coupled inductor on decreasing ripple currents. Fig. 3 shows that, the four inductors in the qZ-source networks and the two inductors in the output filter are coupled. The two output filter inductors $\left(L_{o 1}, L_{o 2}\right)$ are first selected for the analysis because their operation is similar to that of the conventional two-phase interleaved buck converter [7]-[13].

The two main issues of interest in the interleaved buck converter is the inductor (phase) current ripple and output current ripple, which is the sum of the two inductor currents. The current ripples in a non-coupled inductor are first analyzed to compare the ripple reduction effect.

\section{A. Non-Coupled Inductor}

Fig. 6 shows the voltage waveforms across $L_{o 1}$ and $L_{o 2}$. Four operating states are observed. The detailed voltage and

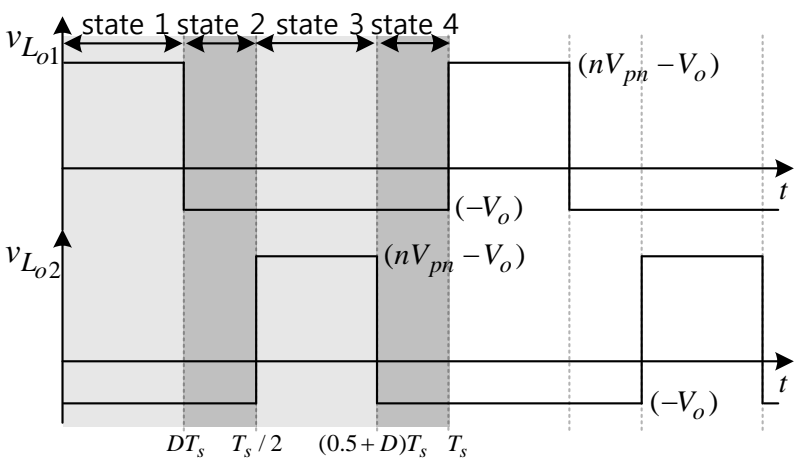

Fig. 6. Voltage waveform of the output filter inductor.

TABLE I

OUTPUT INDUCTOR CURRENT VARIATION OF A NON-COUPLED INDUCTOR

\begin{tabular}{|c|c|c|c|c|}
\hline & State 1 & State 2 & State 3 & State 4 \\
\hline$i_{L_{01}}$ & increasing & decreasing & decreasing & decreasing \\
\hline$i_{L_{o 1}}$ & decreasing & decreasing & increasing & decreasing \\
\hline$i_{o}$ & increasing & decreasing & increasing & decreasing \\
\hline
\end{tabular}

TABLE II

CURRENT RIPPLE COMPARISON

\begin{tabular}{|c|c|c|c|c|}
\hline \multirow{2}{*}{} & \multicolumn{2}{|c|}{ Single-phase } & \multicolumn{2}{c|}{ Two-phase } \\
\cline { 2 - 5 } & $D<0.5$ & $D>0.5$ & $D<0.5$ & $D>0.5$ \\
\hline $\begin{array}{c}\text { Inductor } \\
\text { current } \\
\text { ripple }\end{array}$ & $\frac{V_{o}}{L}(1-D) T_{s}$ & $\frac{V_{o}}{L} D T_{s}$ & $\frac{V_{o}}{L}(1-D) T_{s}$ & $\frac{V_{o}}{L} D T_{s}$ \\
\hline $\begin{array}{c}\text { Output } \\
\text { current } \\
\text { ripple }\end{array}$ & $\frac{V_{o}}{L}(1-D) T_{s}$ & $\frac{V_{o}}{L} D T_{s}$ & $\frac{V_{o}}{L}(1-2 D) T_{s}$ & $\frac{V_{o}}{L}(2 D-1) T_{s}$ \\
\hline
\end{tabular}

current direction in each state is summarized in Table I by assuming that $v_{\text {rec } 1}=v_{\text {rec } 2}=n V_{p n}$.

Given that the two inductors are non-coupled, no interaction occurs between them and the inductor current ripple is calculated as follows:

$$
\begin{gathered}
\Delta i_{L_{o 1}}=\frac{V_{O}}{L_{o 1}}(1-D) T_{s}, \\
\Delta i_{L_{o 2}}=\frac{V_{O}}{L_{O 2}}(1-D) T_{S} .
\end{gathered}
$$

If $L_{o 1}=L_{o 2}=L$, then the inductor current ripple in a non-coupled case is expressed as follows:

$$
\Delta i_{L_{O}}=\frac{V_{O}}{L}(1-D) T_{s} .
$$

Considering that the output current is the sum of $i_{L_{1}}$ and $i_{L_{2}}$, then it increases in State 1 and decreases in State 2. This cycle is repeated in States 3 and 4. Consequently, the output current ripple occurs twice at a given period $T_{s}$. The equation for the output current ripple is as follows:

$$
\Delta i_{O}=\frac{V_{O}}{L}(1-2 D) T_{s} .
$$

Equations (7) to (10) are valid when $D<0.5$. When 


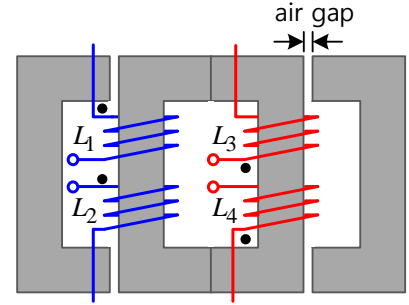

(a) Coupled inductor in qZ-source network.

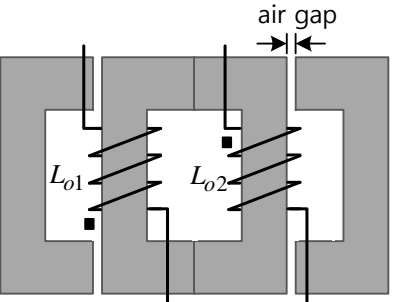

(b) Coupled inductor in output filter.
Fig. 7. Coupled inductor design for the proposed converter

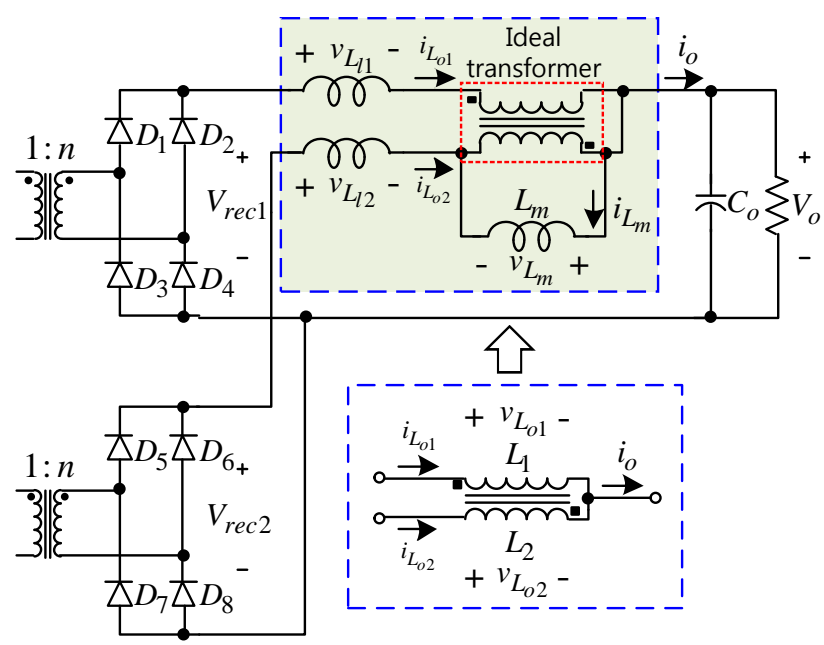

Fig. 8. Secondary side of the proposed converter with a coupled inductor.

$D>0.5$, the equations can be derived similarly as summarized in Table II [7]. The inductor and output current ripples of the two-phase interleaved converter are compared with those of its single-phase counterpart to determine the ripple current reduction effect of the former. The results are summarized in Table II. Unlike in the single-phase converter, the output current ripple in the two-phase case is reduced significantly and its maximum effect is reached when D approaches 0.5. The inductor current ripples, however, remain unchanged [8], [9].

\section{B. Coupled Inductor}

Fig. 7 depicts the proposed coupled inductor structures for both the qZ-source networks and output filter inductors. The secondary side of the transformer of the proposed converter is redrawn (Fig. 8.) to analyze the coupled inductor. The coupled inductor is represented as an ideal 1:1 transformer, two leakage inductances ( $\left.L_{l 1}, L_{l 2}\right)$, and a magnetizing inductance $\left(L_{m}\right)$. Notably, the ideal transformer is connected out of phase with the polarity dots on the opposite ends [8]. Therefore,

$$
i_{L_{m}}=i_{L_{o 1}}-i_{L_{o 2}} .
$$

Similar to in the non-coupled case, four operation states exist in the coupled case. Regardless of the operation states, the following relationships are always applied:

$$
\begin{gathered}
v_{L_{o 1}}=v_{L_{l 1}}+v_{L_{m}}, v_{L_{O 2}}=v_{L_{l 2}}-v_{L_{m}}, \\
v_{L_{m}}=L_{m} \frac{d}{d t}\left(i_{L_{o 1}}-i_{L_{o 2}}\right) .
\end{gathered}
$$

1) State $1\left[0 \sim D T_{s}\right]$ : Based on Figs. 6 and 8, the following equation is applied in State 1:

$$
v_{L_{o 1}}=n V_{p n}-V_{o}, v_{L_{o 2}}=-V_{o} .
$$

From Equations (12) to (14), $v_{L_{l 1}}$ and $v_{L_{l 2}}$ are expressed as follows:

$$
\begin{gathered}
v_{L_{l 1}}=v_{L_{o 1}}-v_{L_{m}}=\left(n V_{p n}-V_{o}\right)-v_{L_{m}}=L_{l 1} \frac{d}{d t} i_{L_{o 1}}, \\
v_{L_{l 2}}=v_{L_{o 2}}+v_{L_{m}}=\left(-V_{o}\right)+v_{L_{m}}=L_{l 2} \frac{d}{d t} i_{L_{o 2}}
\end{gathered}
$$

By assuming that $L_{l 1}=L_{l 2}=L_{l}$ and substituting Equations (15) to (16) into Equation (13), $v_{L_{m}}$ is expressed as follows:

$$
v_{L_{m}}=\left(\frac{L_{m}}{2 L_{m}+L_{l}}\right) n V_{p n} .
$$

Base on Equations (15) to (17), defining $p=L_{m} / L_{l}$ yields the following:

$$
\begin{aligned}
\Delta i_{L_{o 1}} & =\frac{V_{o}}{L_{l}}\left(\frac{1+p}{1+2 p}-D\right) T_{S}, \\
\Delta i_{L_{O 2}} & =\frac{V_{o}}{L_{l}}\left(\frac{p}{1+2 p}-D\right) T_{S} .
\end{aligned}
$$

The output current ripple is expressed as follows:

$$
\Delta i_{o}=\frac{V_{o}}{L_{l}}(1-2 D) T_{s} .
$$

2) State $2\left[D T_{s} \sim T_{S} / 2\right]$ : In State $2, v_{L_{o 1}}=v_{L_{o 2}}=-V_{o}$. Thus,

$$
\begin{aligned}
& v_{L_{l 1}}=v_{L_{o 1}}-v_{L_{m}}=-V_{o}-v_{L_{m}}=L_{l 1} \frac{d}{d t} i_{L_{o 1}}, \\
& v_{L_{l 2}}=v_{L_{o 2}}+v_{L_{m}}=-V_{o}+v_{L_{m}}=L_{l 2} \frac{d}{d t} i_{L_{o 2}} .
\end{aligned}
$$

When Equations (21) to (22) are substituted into Equation (13), then $v_{L_{m}}=0$. Hence,

$$
\begin{gathered}
\Delta i_{L_{o 1}}=\Delta i_{L_{o 2}}=\frac{V_{o}}{L_{l}}\left(\frac{1}{2}-D\right) T_{s}, \\
\Delta i_{o}=\frac{V_{o}}{L_{l}}(1-2 D) T_{S} .
\end{gathered}
$$

3) State $3\left[T_{s} / 2 \sim\left(T_{s} / 2+D T_{s}\right)\right]$

State 3 is similar to State 1 . The only difference is that $v_{L_{o 1}}=-V_{o}$ and $v_{L_{o 2}}=n V_{p n}-V_{o}$. Using methods similar to those in State 1, the inductor and output current ripple in State 3 are derived as follows:

$$
\Delta i_{L_{o 1}}=\frac{V_{o}}{L_{l}}\left(\frac{p}{1+2 p}-D\right) T_{s},
$$


TABLE III

CURRENT Ripple of The Filter InduCtor AND OUtPut

\begin{tabular}{|c|c|c|c|c|}
\hline & State 1 & State 2 & State 3 & State 4 \\
\hline$\Delta i_{L_{o 1}}$ & $\frac{V_{o}}{L_{l}}\left(\frac{1-(k+1) D}{1+k}\right) T_{s}$ & \multirow{2}{*}{$\frac{V_{o}}{L_{l}}\left(\frac{1}{2}-D\right) T_{s}$} & $\frac{V_{o}}{L_{l}}\left(\frac{k-(k+1) D}{1+k}\right) T_{s}$ & \multirow{2}{*}{$\frac{V_{o}}{L_{l}}\left(\frac{1}{2}-D\right) T_{s}$} \\
\cline { 1 - 2 }$\Delta i_{L_{o 2}}$ & $\frac{V_{o}}{L_{l}}\left(\frac{k-(k+1) D}{1+k}\right) T_{s}$ & & $\frac{V_{o}}{L_{l}}\left(\frac{1-(k+1) D}{1+k}\right) T_{s}$ & \\
\cline { 1 - 3 }$\Delta i_{O}$ & \multicolumn{2}{|c}{$\frac{V_{o}}{L_{l}}(1-2 D) T_{s}$} \\
\hline
\end{tabular}

$$
\begin{gathered}
\Delta i_{L_{O 2}}=\frac{V_{O}}{L_{l}}\left(\frac{1+p}{1+2 p}-D\right) T_{s}, \\
\Delta i_{O}=\frac{V_{o}}{L_{l}}(1-2 D) T_{s} .
\end{gathered}
$$

4) State $4\left[\left(T_{s} / 2+D T_{s}\right) \sim T_{s}\right]$ : State 4 is exactly the same as State 2.

According to the state analysis of the coupled inductor, the output current ripple in the coupled case also occurs twice at a given period $T_{s}$. The coupling ratio $p$ does not affect the output current ripple [7]. Equations (10) and (20) show that if $L_{l}$ is equal to the value of the individual inductor $L$ in the non-coupled case, then the output current ripples in both the non-coupled and coupled inductors are the same.

Unlike those in the non-coupled case, the inductor current ripples in the coupled inductor change direction twice per cycle as the output current ripple. The two inductor currents become equal and in-phase as $p$ increases to infinity (perfect coupling). Thus, the coupling ratio $p$ has a significant effect on inductor current ripples, although it does not affect output current ripples [7].

Representing $L_{l}$ and $L_{m}$ in the coupled inductor (or transformer) in terms of the coupling coefficient $k$ rather than the coupling ratio $p$ is more intuitive because we are more familiar with $k$. Based on the general coupled inductor theory, $L_{l}$ and $L_{m}$ are represented as follows [14]:

$$
L_{l}=(1-k) L_{s}, L_{m}=k L_{s},
$$

where $L_{S}$ is the self-inductance of the coupled inductor.

Therefore, the relationship between $p$ and $k$ is as follows:

$$
p=\frac{k}{1-k} \text {. }
$$

Using Equation (29), Equations (18) and (19) can be rewritten as shown in Table III. The inductor current ripple depends on the $D$ and $k$ values. Therefore, the ratio of the inductor current ripple of a coupled inductor $\left(\Delta i_{L, c p}\right)$ normalized with respect to that of a non-coupled inductor $\left(\Delta i_{L, n c}\right)$ is expressed as follows:

$$
\frac{\Delta i_{L, c p}}{\Delta i_{L, n c}}=\frac{1-\left(\frac{D}{1-D}\right) k}{1+k} .
$$

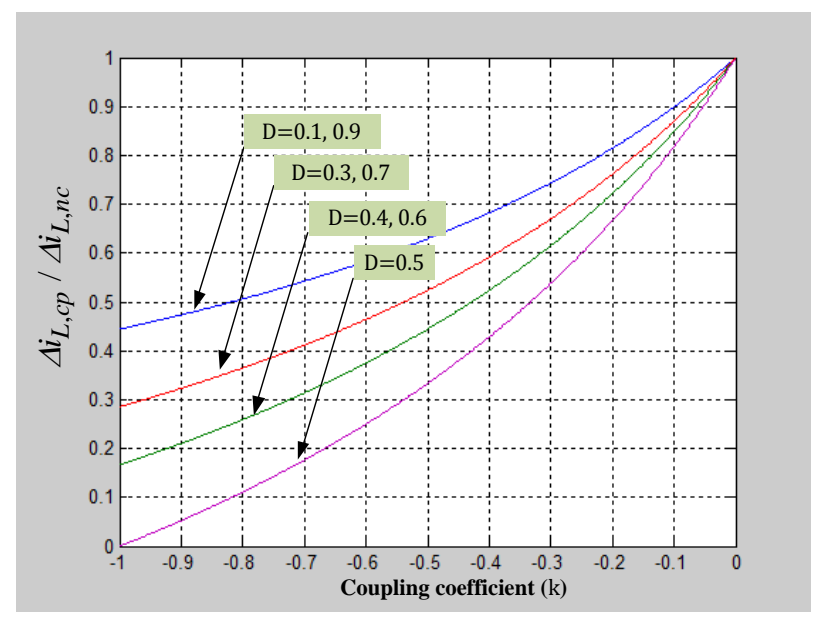

Fig. 9. Inductor current ripple of a coupled inductor normalized with respect to a non-coupled inductor.

The relationship in Equation (30) is plotted in Fig. 9. As shown in the figure, a small current ripple can be achieved with a strong coupling coefficient. The same analysis can be readily applied to the coupled inductor in the qZ-source network. The only difference is the voltage across the qZ-source network inductors.

Fig. 7(a) shows, that the four inductors $\left(L_{1}\right.$ to $\left.L_{4}\right)$ in the qZ-source network are coupled. $L_{1}$ and $L_{2}$ are wound on

the same leg. Similarly, $L_{3}$ and $L_{4}$ are wound on the other leg. Given that the operations of top and bottom qZ-source networks are the same as that of the output coupled inductor, the same ripple reduction effect occurs in the qZ-source inductor currents and in the input current ripple.

\section{EXPERIMENT RESULTS}

A $4 \mathrm{~kW}$ prototype converter is built and tested to verify the performance of the proposed converter. Table IV illustrates the electrical specifications of the proposed converter, including the detailed parameters of the coupled inductors. The transformer turns ratio is set to $1: 1$.

Fig. 10 shows the $4 \mathrm{~kW}$ proposed converter and the photo of the coupled inductor built for this study. similar core structures are used for both the qZ-source inductors and output filter inductors. Figs. 11 and 12 show the transformer 


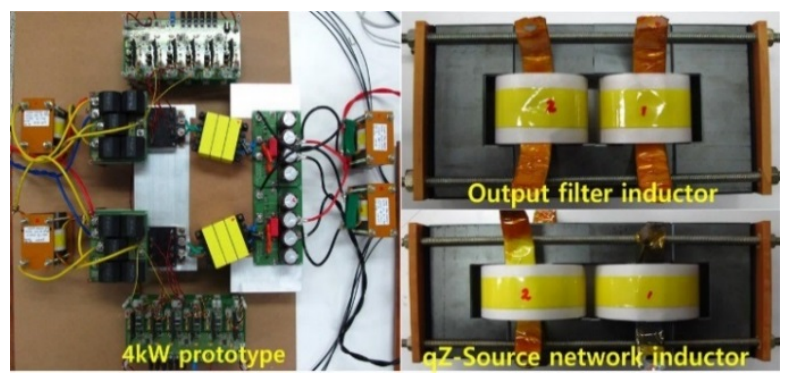

Fig. 10. Photos of the $4 \mathrm{~kW}$ prototype converter and the coupled inductors.

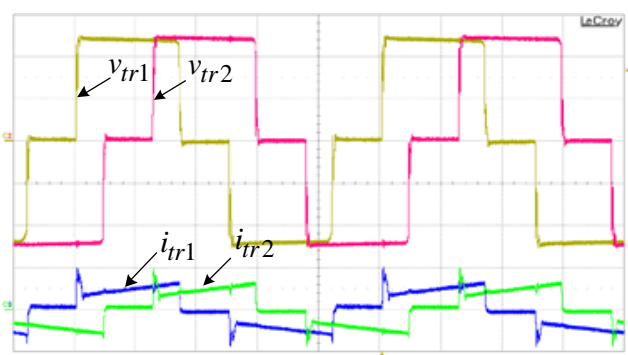

(a) Non-coupled inductor.

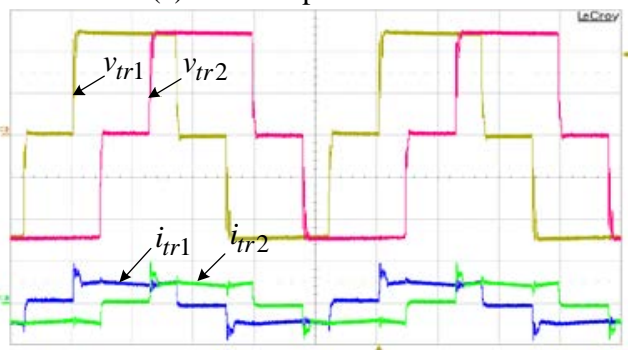

(b) Coupled inductor.

Fig. 11. Waveforms of transformer voltages and currents at buck mode. $\left(v_{\operatorname{tr} 1,2}[250 \mathrm{~V} /\right.$ div. $], i_{\operatorname{tr} 1,2}[10 \mathrm{~A} / \mathrm{div}],.[10 \mu \mathrm{s} / \mathrm{div}],. V_{i}=$ $600 \mathrm{~V}, V_{o}=400 \mathrm{~V}$ and $\left.P_{o}=4 \mathrm{~kW}\right)$

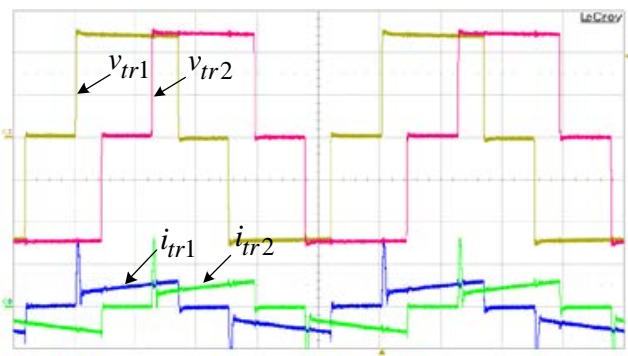

(a) Non-coupled inductor.

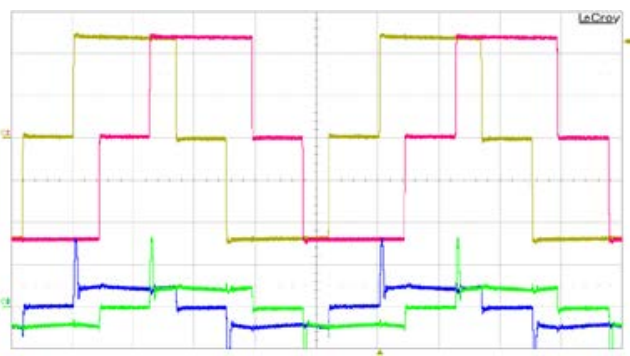

(b) Coupled inductor.

Fig. 12. Waveforms of transformer voltages and currents at boost mode. $\left(v_{\operatorname{tr} 1,2}[250 \mathrm{~V} / \mathrm{div}],. i_{\operatorname{tr} 1,2}[10 \mathrm{~A} / \mathrm{div}],.[10 \mu \mathrm{s} / \mathrm{div}],. V_{i}=\right.$ $200 \mathrm{~V}, V_{o}=400 \mathrm{~V}$ and $P_{o}=4 \mathrm{~kW}$ )

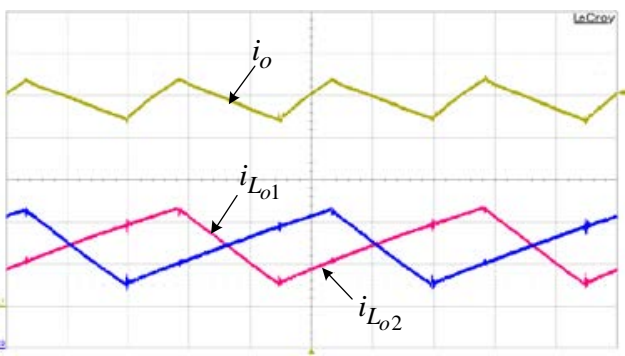

(a) Non-coupled inductor.

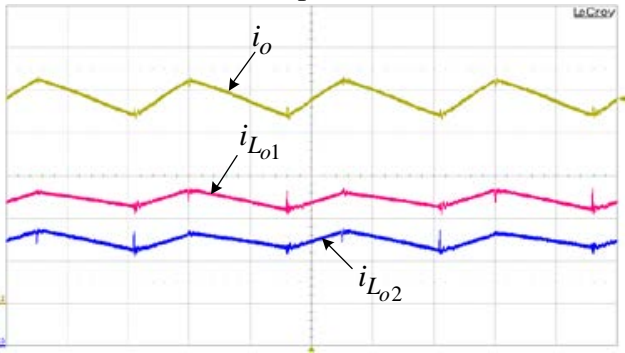

(b) Coupled inductor.

Fig. 13. Waveforms of the output filter inductor and output current. ( $\quad[2 \mathrm{~A} / \mathrm{div}],.[5 \mu \mathrm{s} / \mathrm{div}],. V_{i}=600 \mathrm{~V}, \mathrm{~V}_{o}=400 \mathrm{~V}$, $\left.P_{o}=4 k W\right)$

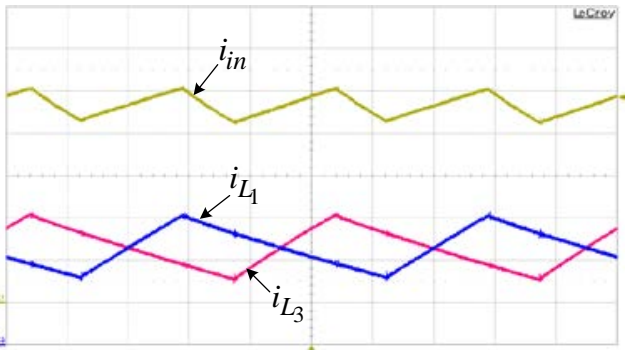

(a) Non-coupled inductor.

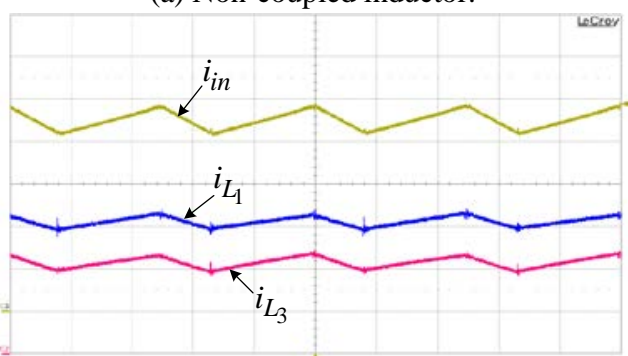

(b) Coupled inductor.

Fig. 14. Waveforms of the qZ-source inductor and input current. ([5A/div. ], [5 $\mu \mathrm{s} / \mathrm{div}.], V_{i}=200 \mathrm{~V}, V_{o}=400 \mathrm{~V}, P_{o}=4 \mathrm{~kW}$ )

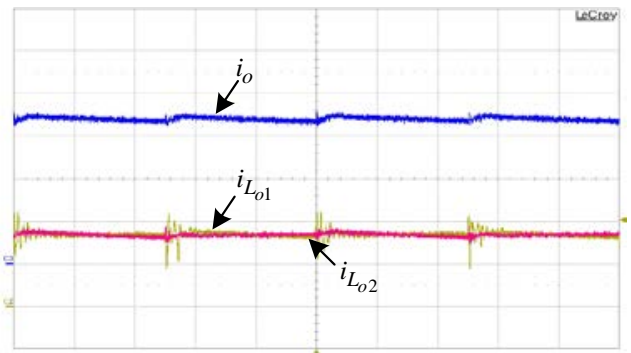

Fig. 15. Waveforms of the output filter inductor and output current. ( $[2 \mathrm{~A} / \mathrm{div}],.[5 \mu \mathrm{s} / \mathrm{div}],. V_{i}=600 \mathrm{~V}, V_{o}=300 \mathrm{~V}$, $D=0.5$ ) 


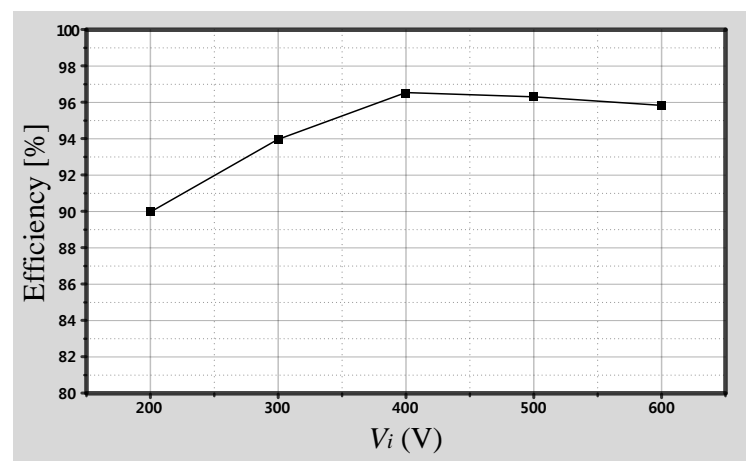

(a) Efficiency vs. input voltage.

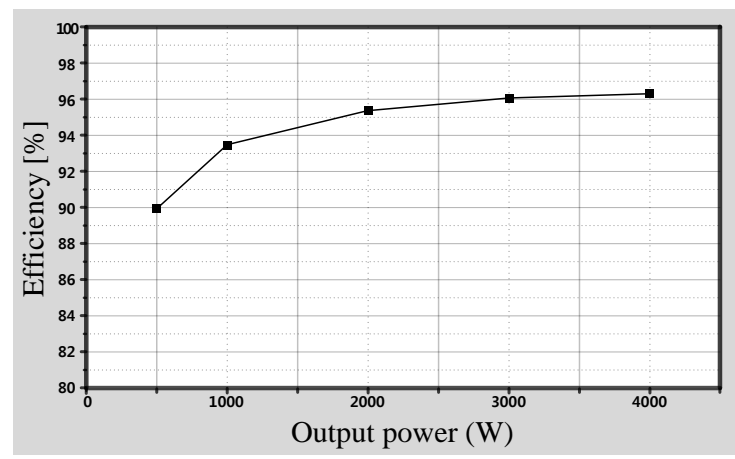

(b) Efficiency vs. output power.

Fig. 16. Efficiency of the proposed converter.

TABLE IV

Electrical Specifications OF THE Proposed CONVERTER AND PARAMETERS OF THE COUPLED INDUCTORS

\begin{tabular}{|c|c|c|}
\hline \multicolumn{2}{|l|}{ Output power } & $4 \mathrm{~kW}$ \\
\hline \multicolumn{2}{|c|}{ Input voltage range } & $200 V_{d c}$ to $600 V_{d c}$ \\
\hline \multicolumn{2}{|l|}{ Output voltage } & $400 V_{d c}$ \\
\hline \multicolumn{2}{|c|}{ Switching frequency } & $20 \mathrm{kHz}$ \\
\hline \multicolumn{2}{|c|}{ Z-source capacitors $\left(C_{1}\right.$ to $\left.C_{4}\right)$} & $50 \mathrm{uF}$ \\
\hline \multirow{2}{*}{$\begin{array}{c}\text { Coupled inductor } \\
\text { in the qZ-source network }\end{array}$} & $L_{1}$ to $L_{4}$ & $210 \mathrm{uH}$ \\
\hline & $k$ & 0.9 \\
\hline \multirow{2}{*}{$\begin{array}{l}\text { Coupled inductor } \\
\text { in the output filter }\end{array}$} & $L_{o 1}, L_{02}$ & $210 \mathrm{uH}$ \\
\hline & $k$ & 0.92 \\
\hline
\end{tabular}

voltage and current waveforms of the proposed converter that operates in buck and boost modes. Given that the transformer current is a reflection of the output filter inductor current, the transformer current waveforms of the coupled case follow the inductor current waveforms.

Fig. 13 shows the current waveforms of the output filter inductor and output currents for both non-coupled and coupled cases. As expected, the inductor current ripples are reduced significantly with the coupled inductor while maintaining the same output current ripple. The two inductor currents are nearly in phase.

Fig. 14 shows the current waveforms of the qZ-source inductors and input currents for both non-coupled and coupled cases. The waveforms are similar to the case of output filter inductors.
Fig. 9 shows that the coupled inductor exhibits the smallest current ripple at $D=0.5$, which can be identified in Fig. 15 .

Fig. 16 shows the efficiency curves of the proposed converter that is measured as input voltage and output power vary.

\section{CONCLUSIONS}

In this study presents a parallel operation of a qZ-source FB DC-DC converter that uses a coupled inductor. With this configuration, the proposed converter exhibits the following features.

- The converter has both buck and boost functions without increasing the switch voltage rating. The output voltage can be larger or smaller than the input voltage. Thus, the proposed converter has a desirable circuit topology when its input voltage range is wide.

- The converter can be short- and open-circuited without damaging switching devices. Therefore, it is resistant to EMI noise. Moreover, its robustness and reliability are significantly improved.

- The converter exhibits all the advantages of paralleling power converters such as modularity, ease of maintenance, $(n+1)$ redundancy, and high reliability.

A $4 \mathrm{~kW}$ prototype that consist of two parallel qZ-source FB DC-DC converters is built and successfully tested to verify the operation principle of the proposed converter.

The converter is as valuable as a renewable energy source with a wide output range. It has an applied battery charge discharge system with a low current ripple. Extending power by parallel connection is also easy. By using buck and boost functions, reducing the current ripple, and realizing its parallel operation, the proposed converter can be a good candidate in such systems because requires wide input voltage variation and exhibits high reliability.

\section{ACKNOWLEDGMENT}

This research was supported by the Kyungpook National University Research Fund, 2013.

\section{REFERENCES}

[1] F. Z. Peng, “Z-source inverter,” IEEE Trans. Ind. Appl., Vol. 39, No. 2, pp. 504-510, Mar./Apr. 2003.

[2] J. Anderson and F. Z. Peng, "Four quasi-Z-Source inverters," in Power Electronics Specialists Conference, (PESC) IEEE, pp. 2743-2749, 2008.

[3] F. Z. Peng, M. Shen, and Z. Qian, "Maximum boost control of the Z-source inverter," IEEE Trans. Power Electron., Vol. 20, No. 4, pp. 833-838, Jul. 2005.

[4] S. Ogasawara, J. Takagaki, H. Magi, and A. Nabae, "A novel control scheme of a parallel current-controlled PWM inverter," IEEE Trans. Ind. Appl., Vol. 28, No. 5, pp.1023-1030, Sep. 1992. 
[5] K. Matsui, Y. Murai, M. Watanabe, M. Kaneko, and F. Ueda, "A pulsewidth-modulated inverter with parallel connected transistors using current-sharing reactors," IEEE Trans. Power Electron., Vol. 8, No. 2, pp. 186-191, Apr. 1993.

[6] F. Ueda, K. Matsui, M. Asao, and K. Tsuboi, "Parallel-connections of pulsewidth modulated inverters using current sharing reactors," IEEE Trans. Power Electron., Vol. 10, No. 6, pp.673-679, Nov. 1995.

[7] W. Pit-Leong, X. Peng, P. Yang, and F. C. Lee, "Performance improvements of interleaving VRMs with coupling inductors," IEEE Trans. Power Electron., Vol. 16, No. 4, pp. 499-507, Jul. 2001.

[8] L. Jieli, C. R. Sullivan, and A. Schultz, "Coupled-inductor design optimization for fast-response low-voltage," in Applied Power Electronics Conference and Exposition (APEC 2002) Seventeenth Annual IEEE, Vol. 2, pp. 817-823, 2002.

[9] W. Pit-Leong, "Performance improvement of multi-channel interleaving VRM with integrated coupling inductors,” Ph. D. Thesis, Virginia Polytechnic Institute and State University, USA, 2000.

[10] L. Jieli, A. Stratakos, A. Schultz, and C. R. Sullivan, "Using coupled inductors to enhance transient performance of multi-phase buck converters," in Applied Power Electronics Conference and Exposition, (APEC '04) Nineteenth Annual IEEE, Vol. 2, pp. 1289-1293, 2004.

[11] H. B. Shin, J. G. Park, S. K. Chung, H. W. Lee, and T. A. Lipo, "Generalised steady-state analysis of multiphase interleaved boost converter with coupled inductors," Electric Power Applications, IEE Proceedings, Vol. 152, pp. 584-594, 2005.

[12] P. Zumel, O. Garcia, J. A. Cobos, and J. Uceda, "Magnetic integration for interleaved converters," in Applied Power Electronics Conference and Exposition, (APEC'03) Eighteenth Annual IEEE, Vol. 2, pp. 1143-1149, 2003.

[13] L. Yim-Shu, W. Leung-Pong, and D. K. W. Cheng, "Simulation and design of integrated magnetics for power converters,” IEEE Trans. Magn., Vol. 39, No. 2, pp. 1008-1018, Mar. 2003.

[14] A. F. Witulski, "Introduction to modeling of transformers and coupled inductors,” IEEE Trans. Power Electron., Vol. 10, No. 3, pp. 349-357, May 1995.

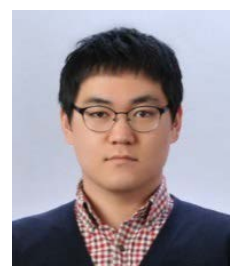

Hyeongmin Lee was born in 1982. He received his B.S. in Electronics Engineering and M.S. in Electrical Engineering from Kyungpook National University, Daegu, Korea, in 2011 and 2013, respectively. He is currently working toward a Ph.D. in electrical Engineering. His research interests are power conversion systems and power

control systems.

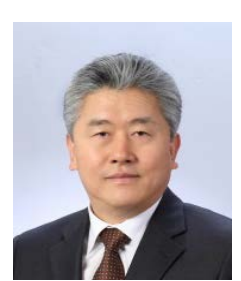

Heung-Geun Kim was born in Korea in 1956. He received his B.S., M.S., and Ph.D. in Electrical Engineering from Seoul National University in 1980, 1982 and 1988, respectively. He has been with the Department of Electrical Engineering at Kyungpook National University since 1984, where he is currently a full professor and the director of the Microgrid Research Center. He was a visiting scholar at the Department of Electrical and Computer Engineering of the University of Wisconsin-Madison from 1990 to 1991 and the Department of Electrical Engineering of Michigan State University, USA from 2006 to 2007. His current research interests include AC machine control, PV power generation, and micro-grid systems.

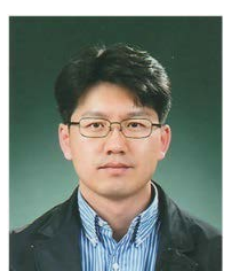

Honnyong Cha received his B.S. and M.S. in Electronics Engineering from Kyungpook National University, Daegu, Korea, in 1999 and 2001, respectively, and Ph.D. in Electrical Engineering from Michigan State University, East Lansing, Michigan, USA in 2009. He was a research engineer with the PSTEK, An-san, Korea from 2001 to 2003. He also worked as a senior researcher at the Korea Electrotechnology Research Institute, Changwon, Korea from 2010 to 2011. He joined Kyungpook National University as an assistant professor at the School of Energy Engineering in 2011. His main research interests include high power DC-DC converters, DC-AC inverters, Z-source inverters, and power conversion for electric vehicles and wind power generation.

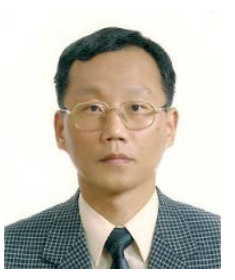

Tae-Won Chun was born in Korea in 1959. He received his B.S in Electrical Engineering from Pusan National University in 1981 and his M.S. and Ph.D. in Electrical Engineering from Seoul National University in 1983 and 1987, respectively. He has been a member of the faculty of the Department of Electrical Engineering, Ulsan University, where he is currently a full professor since 1986 . He was a visiting scholar at the Department of Electrical and Computer Engineering, University of Tennessee, USA. He was also a visiting scholar with the Department of Electrical and Computer Engineering, Virginia Polytechnic Institute and State University, USA from 2005 to 2006. His current research interests include grid-connected inverter systems and AC motor control.

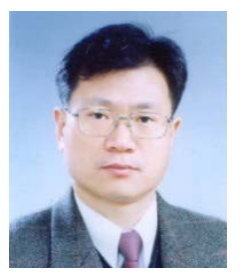

Eui-Cheol Nho was born in Korea in 1960. He received his B.S. in Electrical Engineering from Seoul National University, Korea in 1984, and his M.S. and Ph.D. in Electrical and Electronics Engineering from KAIST, Korea, in 1986 and 1991, respectively. He worked with Powertech Co., Ltd., Korea, as the chief of its R\&D center from 1991 to 1995 . He has been a faculty member at the Department of Electrical Engineering, Pukyong National University since 1995. He was a visiting scholar at the Department of Electrical and Computer Engineering, University of Wisconsin, Madison, USA from 1997 to 1998 and at the Department of Electrical Engineering and Computer Science, University of California, Irvine, USA from 2005 to 2006. His current research interests include high voltage PWM converter, soft-switching converters, energy storage systems, hybrid generation systems, and power line conditioners. 